

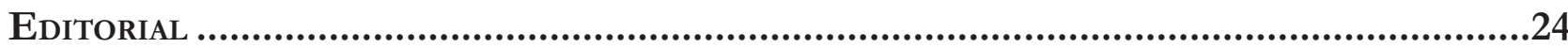

O Direito na fronteira da razão: Psicologia, neurociência e economia comportamental................... 24 Patrícia Perrone Campos Mello e Sergio Nojiri

I. NeURodireito: COGNIÇão, EMOÇÃo, JUÍZOS MORAIS E CIÊNCIA ..........................................26

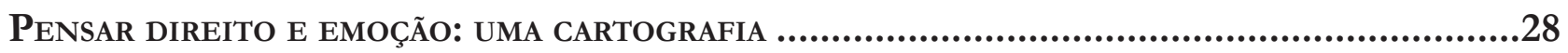

Nevita Maria Pessoa de Aquino Franca Luna

Neurodireito: o início, o fim E O MEIO

Carlos Marden e Leonardo Martins Wykrota

ENSAIO JURÍDICO SOBRE A RACIONALIDADE HUMANA: MAIORES, CAPAZES E IRRACIONAIS

André Perin Schmidt Neto e Eugênio Facchini Neto

DIVERGÊNCIAS DE PRINCÍPIO: ARGUMENTOS JURÍDICOS E MORAIS EM UM CENÁRIO DE DESACORDOS SOCIAIS

André Matos de Almeida Oliveira, Pâmela de Rezende Côrtes e Leonardo Martins Wykrota

CONSILIÊNCIA E A POSSIBILIDADE DO NEURODIREITO: DA DESCONFIANÇA À RECONCILIAÇÃO DISCIPLINAR.....

Thaís de Bessa Gontijo de Oliveira e Renato César Cardoso

MODELOS DE MORALIDADE

Molly J. Crockett

A INFELIZ BUSCA POR FELICIDADE No DiREITo

Úrsula Simões da Costa Cunha Vasconcellost, Noel Struchiner e Ivar Hannikainen

Além da liberdade: PersPeCtivas Em Nietzsche.

Lucas Costa de Oliveira

A mediaÇão de CONFlitos SOb a PERSPECTIVA do DESENVOLVIMENTO HUMANO: AS CONTRIBUIÇÕES DA PSICOLOGIA POSITIVA

Simone de Biazzi Ávila Batista da Silveira e Deise Brião Ferraz

Neuroimagiologia e aValiação de ResPonsabilidade

Nicole A. Vincent 
ANÁLISE CRÍTICA DA ORIENTAÇÃO DE CIDADÃOS COMO MÉTODO PARA OTIMIZAR DECISÕES PÚBLICAS POR MEIO DA TÉCNICA NUDGE.

Luciana Cristina Souza, Karen Tobias França Ramos e Sônia Carolina Romão Viana Perdigão

Políticas públicas e o deVer de monitoramento: “LEVANdo os Direitos A SÉrio". .252 Ana Paula de Barcellos

Nudges E POLÍticas PÚblicas: uM MECANISMO DE COMBATE AO TRABALHO EM CONDIÇÃo ANÁLOGA À DE ESCRAVO .267

Amanda Carolina Souza Silva, Débhora Renata Nunes Rodrigues e Saul Duarte Tibaldi

REDUZINDO A TRIBUTAÇÃO COGNITIVA: LIÇÕES COMPORTAMENTAIS PARA A DIMINUIÇÃO DOS EFEITOS PSICOLÓGICOS ADVERSOS DA POBREZA.............................................................288 Leandro Novais e Silva, Luiz Felipe Drummond Teixeira, Gabriel Salgueiro Soares e Otávio Augusto Andrade Santos

Políticas PÚBLICAS EM SUICÍDIO: DO PATERNALISMO CLÁSSICO AO PATERNALISMO LIBERTÁRIO E NUDGING

Davi de Paiva Costa Tangerino, Gabriel Cabral e Henrique Olive

Nudges COMO POLÍticA PÚbliCA PARA AUMENTAR O ESCASSO NÚMERO DE DOADORES DE ÓRGÃos PARA TRANSPLANTE

Roberta Marina Cioatto e Adriana de Alencar Gomes Pinheiro

Os PROGRAMAS DE INTEGRIDADE PARA CONTRATAÇÃO COM A ADMINISTRAÇÃO PÚBLICA ESTADUAL: NUDGE OU OBRIGAÇÃo LEGAL? UM OLHAR SOBRE AS DUAS PERSPECTIVAS .386

Cíntia Muniz Rebouças de Alencar Araripe e Raquel Cavalcanti Ramos Machado

Paternalismo libertário e Proteção JURídica do AMbiente: POR QUe PROTEger o AMBIENTE TAMBÉM DEVE SER PROTEGER AS LIBERDADES?

Mariana Carvalho Victor Coelho e Patryck de Araujo Ayala

Políticas PÚblicas baseadas EM EVIdÊNCIAS COMPORTAMENTAIS: REFLEXões A PARTIR do Projeto de Lei 488/2017 do Senado

Pâmela de Rezende Côrtes, André Matos de Almeida Oliveira e Fabiano Teodoro de Rezende Lara

III. ECONOMIA COMPORTAMENTAL: VIESES COGNITIVOS E POLÍTICAS PÚBLICAS .455

ECONOMIA COMPORTAMENTAL E DIREITO: A RACIONALIDADE EM MUDANÇA Marcia Carla Pereira Ribeiro e Victor Hugo Domingues

VIESES COGNITIVOS E DESENHO DE POLÍTICAS PÚBLICAS 
A neurociênCia da moralidade na tomada de DeCisões Jurídicas Complexas e No DESENHO DE POLÍTICAS PÚBLICAS

Erik Navarro Wolkart

Desvio de CARÁter ou SIMPLESMENTE HUMANO? ECONOMIA COMPORTAMENTAL APLICADA AO COMPORTAMENTO DESONESTO

Diana Orghian, Gabriel Cabral, André Pinto e Alessandra Fontana

Políticas Públicas e a ConcretizaÇão de direitos sociais: TOMAdA DE DECisão, ARQUITETURA DE ESCOLHAS E EFETIVIDADE

Ana Elizabeth Neirão Reymão e Ricardo dos Santos Caçapietra

BEHAVIORAL ECONOMICS E DIREITO DO CONSUMIDOR: NOVAS PERSPECTIVAS PARA O ENFRENTAMENTO DO SUPERENDIVIDAMENTO .568

Samir Alves Daura

A EDUCAÇÃo FORMAL PARA O CONSUMO É GARANTIA PARA UMA PRESENÇA REFLETIDA DO CONSUMIDOR NO MERCADO? UMA ANÁLISE COM BASE NA BEHAVIORAL LAW AND ECONOMICS (ECONOMIA COMPORTAMENTAL) 600

Marcia Carla Pereira Ribeiro e Edson Mitsuo Tiujo

LIBET, DETERMINISMO E CONSUMO: AS INFLUÊNCIAS DO MARKETING E A RELEVÂNCIA DA DELIBERAÇÃo CONSCIENTE NA SUPERAÇÃo CONDICIONAL DE HÁBITOS DE CONSUMO PERIGOSOS616 Émilien Vilas Boas Reis e Leonardo Cordeiro de Gusmão

CiÊNCIA DO DIREITO TRIBUTÁRIO, ECONOMIA COMPORTAMENTAL E EXTRAFISCALIDADE. .640 Hugo de Brito Machado Segundo

IV. CoMportamento JUdiCiAL: INFLUÊNCIA DE FATORES EXTRAJURÍDicos .660

FATORES METAPROCESSUAIS E SUAS INFLUÊNCIAS PARA A FORMAÇÃo DA DECISÃo JUDICIAL .662 Rogério Roberto Gonçalves de Abreu, Lúcio Grassi de Gouveia e Virgínia Colares

“A VIDA COMO ELA É": COMPORTAMENTO ESTRATÉGICO NAS CORTES Patrícia Perrone Campos Mello

A COMPOSIÇÃo do ÓRGão COLEGIAdo E SEUS EFEITOS NA TOMADA DE DECISÃo .720 André Garcia Leão Reis Valadares

Das 11 ilhas ao centro do arquipélago: os superpoderes do Presidente do STF DURANTE O RECESSO JUDICIAL E FÉRIAS .741 José Mário Wanderley Gomes Neto e Flávia Danielle Santiago Lima 
RAZÃo, EMOÇÃo E DELIBERAÇÃO: AS ADEQUAÇÕES REgIMENTAIS do SUPERIOR TribUNAL DE JUSTIÇA PARA A FORMAÇÃo DE PRECEDENTES EFICAZES

Peter Panutto e Lana Olivi Chaim

Heurística de ancoragem e fiXaÇÃo de danos morais em JUizados especiais Cíveis no Rio DE JANEIRO: UMA NOVA ANÁLISE 778

Fernando Leal e Leandro Molhano Ribeiro

LA PROTECCIÓN DE LOS DERECHOS POLÍTICOS FRENTE A LAS FUNCIONES DISCIPLINARIAS DE LAS AUTORIDADES ADMINISTRATIVAS: SUBSIDIARIEDAD Y DEFERENCIA EN EL SISTEMA INTERAMERICANO DE DERECHOS HUMANOS Jorge Ernesto Roa Roa

V. A influênCia do gÊNERo no PROCESSO DECisório JUdiCial

Como os Juízes decidem os Casos de estupro? ANALISANDo SENTENÇAS SOb A PERSPECTIVA DE VIESES E ESTEREÓTIPOS DE GÊNERO 826 Gabriela Perissinotto de Almeida e Sérgio Nojiri

GÊNERO E COMPORTAMENTO JUDICIAL NO SUPREMO TRIBUNAL FEDERAL: OS MINISTROS CONFIAM MENOS EM RELATORAS MULHERES?

Juliana Cesario Alvim Gomes, Rafaela Nogueira e Diego Werneck Arguelhes

Hércules, Hermes e a Pequena Sereia: uma reflexão sobre estereótipos de gênero, SUBPRESENTAÇÃo DAS MULHERES NOS TRIBUNAIS E (I)LEGITIMIDADE DEMOCRÁTICA DO PODER JUDICIÁRIO. .878 Jane Reis Gonçalves Pereira e Renan Medeiros de Oliveira

Prisão Cautelar de gestantes: análise do Fundamento filosófico da decisão do Habeas CoRpus N. 143.641 912

Artur César Souza e Giovania Tatibana de Souza

VI. Neurodireito APlicado ao direito E Ao Processo PENAL....................................926

CÉREbros QUe PUNEM: UMA REVISÃo CRÍTICA DA NEURoCIÊNCIA DA PUNIÇÃo .....................928 Ricardo de Lins e Horta

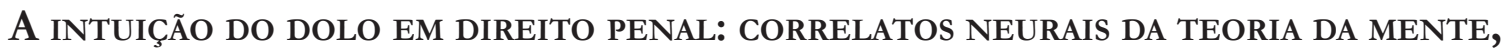
RACIOCÍNIO INDUTIVO E A GARANTIA DA CONVICÇÃO JUSTIFICADA. .946 Thiago Dias de Matos Diniz e Renato César Cardoso

As COMUNIDADES EPISTÊMICAS PENAIS E A PRODUÇÃo LEGISLATIVA EM MATÉRIA CRIMINAL..... 961 Stéphane Enguéléguélé 
DELINQUÊNCIA JUVENIL: RELAÇÕES ENTRE DESENVOLVIMENTO, FUNÇÕES EXECUTIVAS E COMPORTAMENTO SOCIAL NA ADOLESCÊNCIA .

André Vilela Komatsu, Rafaelle CS Costa e Marina Rezende Bazon

Límites TEMPORALES A LAS PENAS PRIVATIVAS DE LIBERTAD ATENDIENDO AL DESARROLLO PSICOSOCIAL.

Silvio Cuneo Nash

NEURolaw E AS PERSPECTIVAS PARA UMA ANÁLISE OBJETIVA DO COMPORTAMENTO SUGESTIONADO: REPERCUSSÃO DAS FALSAS MEMÓRIAS NA ESFERA PENAL

Mariana Dionísio de Andrade, Marina Andrade Cartaxo e Rafael Gonçalves Mota

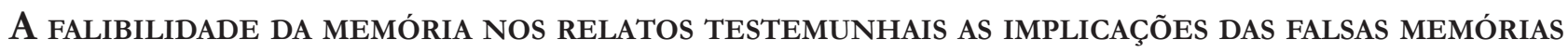
NO CONTEXTO DOS CRIMES CONTRA A DIGNIDADE SEXUAL

Caroline Navas Viana

A (IR)REPETIBILIDADE dA PROVA PENAL DEPENDENTE DA MEMÓRIA: UMA DisCUSSÃo COM BASE NA PSICOLOGIA DO TESTEMUNHO. 1058

William Weber Cecconello, Gustavo Noronha de Avila e Lilian Milnitsky Stein 


\title{
Desvio de caráter ou simplesmente humano? Economia comportamental aplicada ao comportamento desonesto*
}

\author{
Bad character or simply human? Behavioral \\ economics applied to dishonest behavior
}

\author{
Diana Orghian** \\ Gabriel Cabral*** \\ André Pinto**** \\ Alessandra Fontana*****
}

* Artigo convidado

** Doutorada em Cognição Social na Faculdade de Psicologia da Universidade de Lisboa. Investigadora no Media Lab, Massachussetts Institute of Technology (MIT). Conselheira Cientifica (Scientific Advisor) em CLOO Behavioral Insight Unit. E-mail: dorghian@mit. edu.

*** Professor substituto de Direito da Universidade Federal do Rio de Janeiro (UFRJ), Mestre em direito pela Pontifícia Universidade Católica do Rio de Janeiro (PUC-RJ). Consultor em CLOO Behavioral Insight Unit. E-mail: gcabral@cloo.pt.

**** Psicólogo Social e Mestre integrado em Cognição Social Aplicada pela Faculdade de Psicologia da Universidade de Lisboa. Consultor em CLOO Behavioral Insight Unit. E-mail: apinto@cloo.pt.

***** Jornalista pela Pontifícia Universidade Católica de Paraná e Mestre em Relações Internacionais e Desenvolvimento pela University of East Anglia (UK). Pesquisadora e colaboradora em CLOO Behavioral Insight Unit. Email: alessandrafontana@hotmail.com.

\section{Resumo}

Neste artigo, apresentamos uma abordagem de combate à corrupção e ao comportamento desonesto baseada na economia comportamental, psicologia cognitiva e psicologia social. A economia comportamental tem sido extensivamente aplicada à criação de políticas de alteração de comportamentos na área da saúde e educação, sendo a aplicação ao combate à corrupção uma área ainda incipiente. Neste artigo, tendo por base uma revisão da literatura científica sobre o comportamento desonesto, demonstramos que as pessoas nem sempre agem de forma racional, coerente e previsível, e nem sempre incorporam análises de custo-benefício nas suas decisões, tal como é previsto pelos modelos econômicos tradicionais. Também, demonstramos que existem fatores inconscientes e mais sutis que podem estar contribuindo para o comportamento desonesto. Esses fatores são: i) a cognição humana e os vieses que afetam a tomada de decisão (e.g. racionalização motivada, licença moral, dissonância cognitiva etc.); ii) as características do contexto que influenciam determinado comportamento desonesto (e.g. ambiguidade nos procedimentos, falta de clareza, distância psicológica em relação ao dinheiro etc.); iii) os fatores sociais que podem ser relevantes ao comportamento desonesto (reciprocidade, difusão da responsabilidade, normas sociais etc.). Uma vez conhecidos estes fatores, um rol de intervenções pode ser sugerido para conduzir as pessoas a agirem de forma mais honesta. Este artigo é direcionado a atores do setor público e privado interessados na temática do combate à corrupção e tem dois objetivos: i) descrever os fatores psicológicos que influenciam o comportamento desonesto e ii) apresentar soluções de fácil implementação e baixo custo (nudges), que podem ser integradas nas políticas de integridade e combate à corrupção.

Palavras-chave: Economia comportamental. Heurísticas. Desonestidade. Nudge. 


\section{Abstract}

In this paper we present a human-centered approach to fighting corruption inspired by behavioral economics, cognitive and social psychology. Behavioral Science has been used extensively to design policies in areas such health and education. However, their application to dishonest behavior has been incipient. The current policy approaches to corruption follow mostly a traditional 'rational' model of behavior. Here, we argue that people do not always incorporate cost-benefit analysis in their decisions and they have unconscious biases and heuristics driving their dishonest behaviors. Knowing how these biases operate is a crucial step to understand why corrupt behavior happens and how we can discourage it more effectively. Our approach to corruption analyses three components influencing human behavior: i) human cognition and biases that affect decision making (motivated reasoning, moral licensing, cognitive dissonance, etc.); ii) the attributes of the context that push us toward dishonest behavior (ambiguity in the procedures, lack of clarity of consequences, psychological distance to money, etc.); iii) the social factors that lead us to behave unethically (reciprocity, diffusion of responsibility, social norms, etc.). These factors can be intervened in order to nudge people towards ethical actions, improving the effectiveness of anti-corruption policies and increasing trust. This paper targets public and private sector stakeholders interested in fighting corruption, and its goal is two-folded: i) to describe the major psychological factors that affect lead to dishonest behaviors, and ii) present a set of effective solutions that can be easily implemented at low cost within public and private policy.

Keywords: Behavioral science. Heuristics. Dishonesty. Nudge.

\section{INTRODUÇÃo}

Os comportamentos desonestos afetam a sociedade em diversos níveis, desde a violação de regras internas no local de trabalho (e.g. declarar despesas excessivas de viagens) ou violação de deveres fiscais (e.g. a evasão fiscal e o não pagamento de multas), até ações fraudulentas com consequências mais sistêmicas (e.g. lavagem de dinheiro, superfaturamento de obras públicas ou desvio de dinheiro público).

No Brasil, o tema do combate à corrupção se tornou objeto de atenção generalizada em decorrência de investigações policiais altamente midiatizadas, como a Lava Jato. No Fórum Econômico Mundial para a América Latina de 20181, o Ministro Torquato Jardim afirmou que "O que se conhece da Lava Jato é 10\%, é a ponta do iceberg”. Diante de afirmações dramáticas como esta, indaga-se: que estratégias utilizar para combater a corrupção e como tornar essas estratégias mais eficazes? A corrupção é um problema complexo e, como tal, demanda respostas holísticas.

Estratégias de combate à corrupção devem incorporar elementos de natureza variada, desde programas de prevenção à esforços de criminalização, de atos da administração pública a iniciativas dos cidadãos e do setor privado. As intervenções empreendidas no setor público e privado para resolver o problema podem ser diversas: aumentar a fiscalização, aumentar as penas para crimes de corrupção, privatizar os serviços públicos, promover campanhas de conscientização da população, realizar cursos de treinamento, reciclagem ética de agentes públicos etc.

Em um cenário de muito ressentimento, é compreensível que as políticas públicas mais tradicionais de combate à corrupção ganhem espaço na opinião pública: de um lado, mais denúncia, investigação e punição; de outro, mais conscientização, informação e educação. Como uma ilustração desse fenômeno, mais de duas milhões de pessoas assinaram o projeto de Iniciativa Popular criada pelo Ministério Público Federal (MPF),

1 FÓRUM Econômico Mundial para América Latina 2018. Disponível em: <https://www.weforum.org/es/focus/forum-economico-mundial-para-a-america-latina-2018>. Acesso em: 21 maio 2018. 
intitulado 10 medidas contra a corrupção ${ }^{2}$. Ilustrativo do investimento na punição, no banner referente às medidas, apresentam-se frases como as seguintes: "[é preciso] quebrar o círculo de impunidade" e "corrupção será um crime de alto risco!".

A segunda tendência diz respeito à criação de departamentos de compliance em empresas e a implementação de programas de integridade em órgãos públicos. As estratégias de compliance e integridade, diferentemente das 10 medidas do MPF, não possuem, apenas, um aspecto persecutório e punitivo, mas também um aspecto pedagógico, informativo, e de esclarecimento de condutas ilícitas e indesejadas. Essa difusão deve-se, majoritariamente, à vigência, a partir de 2014, da "Lei Anticorrupção" (Lei 12.846/13), que, grosso modo, prevê a responsabilização objetiva de empresas em casos de práticas de atos lesivos contra a Administração Pública, como a corrupção ativa. Seguindo essa linha, dois anos depois, por meio da Portaria n ${ }^{\circ} 748 / 16$, foi instituído o Programa de Fomento da Integridade Pública da Controladoria-Geral da União (PROFIP), cuja principal função é orientar e capacitar órgãos do Poder Executivo Federal e empresas aderentes ao Programa a criar medidas de compliance $e^{3}$.

Assim, atualmente no Brasil, tem-se, de um lado, o MPF e outras instâncias públicas, como os Tribunais de Contas, apostando na vigilância e punição; e, de outro lado, a CGU, que por meio do PROFIP, aposta na educação e informação como meios para combater a corrupção ${ }^{4}$. Diante desse quadro, a questão que fazemos é: será que essas apostas são baseadas em pressupostos realistas sobre o comportamento humano? Será que há algum mecanismo que possa potencializar o efeito dessas medidas ou, ainda, que apresente um caminho alternativo, ou complementar, entre punir e informar?

O ser humano como ser racional serve de guia a muitos dos modelos de análise de comportamento empregados na Economia tradicional ou Neoclássica. Nesses modelos, os seres humanos são descritos como seres que agem de acordo com a Teoria da Ação Racional ${ }^{5}$. No contexto do crime, um modelo frequentemente utilizado para explicar as razões pelas quais as pessoas cometem crimes é o Simple Model of Rational Crime on Rational crime theory ${ }^{6}$. De acordo com esse modelo, a decisão de cometer um crime resulta de uma análise de custo-benefício realizada com base nas informações a que se têm acesso. Assim, o indivíduo comete o crime se a recompensa for maior do que os potenciais malefícios, nomeadamente: a chance de a pessoa ser descoberta, a chance de ser condenada criminalmente e, em caso de condenação, o montante da pena.

Em consonância com esse paradigma racional, para que um agente público venha a se corromper, basta que os benefícios de sua corrupção sejam maiores do que as possíveis penalizações decorrentes da persecução sancionatória. Isto significa que, se medidas severas contra a corrupção forem aplicadas, cometer atos corruptos será mais custoso, e, como consequência, as pessoas deixarão de cometer esse crime.

Mas será mesmo assim? Não negamos que existam momentos em que o ser humano se comporte segundo esse modelo racional, há décadas utilizado na política criminal. Entretanto, apesar de intuitivo e sedutor, esse modelo vem sendo alvo de constantes críticas por não subsistir a um contraste com a realidade. As críticas decorrem das assunções que o modelo racional faz relativamente à natureza humana ${ }^{7}$. Além da natureza

2 Consultar: <http://www.dezmedidas.mpf.mp.br/campanha/produtos/pdf/Banner_LONA.pdf>. Acesso em: 21 maio 2018.

3 O manual do PROFIP de apoio elaborado pela CGU pode ser encontrado em: <http://www.cgu.gov.br/Publicacoes/etica-eintegridade/arquivos/manual_profip.pdf/view>; Acesso em: 25 jul. 2018.

4 Existe, ainda, a atuação da sociedade civil e da mídia que, também, executam investigação, informação e conscientização e são parte do arcabouço anticorrupção da maioria dos países democráticos. Entretanto, como esse texto se dedica a analisar políticas públicas desenhadas e implementadas por órgãos públicos, não analisamos os impactos da economia comportamental sobre as atividades desses atores.

5 Há como alternativa, por exemplo, o homo sociologicus, que enfatiza o homem como resultado das pressões sociais ou o homo reciprocans, em que o caráter de reciprocidade e cooperação humana são salientados.

6 HARFORD, Tim. The logic of life: the rational economics of an irrational world. New York: Random House, 2008 e CLARKE, Ronald; FELSON, Marcus. Routine activity and rational choice: advances in criminological theory, v. 5, 1993.

7 Cf. PERSSON, Anna; ROTHSTEIN, Bo; TEORELL, J. Why anticorruption reforms fail: systemic corruption as a collective action problem. Governance, New Jersey, v. 26, n. 3, p. 449-471, jul. 2013. 
complexa inerente à problemática da corrupção, muitos dos comportamentos desonestos que conduzem a atos corruptos devem-se a vieses ${ }^{8}$ que operam de forma inconsciente ${ }^{9}$. Perante vieses inconscientes, criar mais regras, leis, ou sanções, bem como dar mais informações às pessoas, pode ter pouco ou nenhum impacto no comportamento. A boa notícia é que é possível conhecer esses vieses, entender como operam e criar intervenções eficazes para combatê-los. Nesta análise, apresentaremos alguns dos vários fatores cognitivos, contextuais e sociais que podem promover comportamentos desonestos.

\section{ECONOMIA COMPORTAMENTAL: UMA BASE TEÓRICA DIFERENTE PARA FUNDAMENTAR AÇÕES PRÁTICAS CONTRA A CORRUPÇÃO}

A Economia Comportamental é o domínio científico que resulta do cruzamento entre a Psicologia, em particular a Psicologia Social e a Psicologia Cognitiva, e a Economia, tendo como principal objetivo estudar a tomada de decisão do ponto de vista comportamental. A economia comportamental tem o mérito de aproximar teorias econômicas, tradicionalmente abstratas e teóricas, de evidências das ciências comportamentais. Um bom sinal dessa aproximação entre psicologia e economia é o fato de o psicólogo Daniel Kahneman ter ganhado o Prêmio Nobel da Economia em $2002^{10}$ pelas suas descobertas relativamente ao julgamento humano e tomada de decisão em situações de incerteza. Mais recentemente, o mesmo prêmio foi atribuído em 2017 a Richard Thaler, economista que utiliza a Economia Comportamental não apenas para compreender o comportamento humano, mas também como um meio para desenvolver políticas públicas mais eficazes e baseadas em evidências científicas (nudges).

Para cientistas comportamentais, os seres humanos não são tão racionais quanto retratam os modelos tradicionais, dispondo de uma racionalidade limitada (bounded rationality), conceito introduzido por Herbert Simon $^{11}$. Para Simon, a própria ideia de determinar qual é a opção mais racional constitui um custo que a torna irracional. Conseguir as informações necessárias a uma decisão racional, processá-la atentamente, computar todas as opções e calcular os prós e contras de cada uma são tarefas exigentes em termos cognitivos e requerem tempo. Tendo em vista esse claro custo cognitivo, Simon afirma que as pessoas acabam tomando uma decisão que não é perfeita, mas é satisfatória ${ }^{12}$ (“good enough"). Essa decisão é a mais racional diante de nossas limitações, pois: (i) falta-nos tempo para refletir sobre todas as opções disponíveis, (ii) nem sempre temos acesso a todas as informações necessárias e (iii) nosso cérebro tem limitações em termos da quantidade que consegue computar. Além dessas limitações, a investigação mostra que somos afetados por vieses cognitivos: mecanismos psicológicos simplificados, muitas vezes automáticos, que guiam o nosso comportamento e a nossa tomada de decisão, e que em certas situações se afastam, consideravelmente, do que seria considerado adequado de um ponto de vista racional.

Além de não considerar a nossa racionalidade limitada e os vieses cognitivos, o modelo do agente racional não considera uma das motivações mais características do ser humano, e que tem grande relevância para o comportamento desonesto: a nossa necessidade de manter uma imagem positiva de nós mesmos e perante

8 Vieses cognitivos são mecanismos cognitivas de simplificação da informação que conduzem a tendências comportamentais previsíveis e sistemáticos. No livro Thinking fast and slow (2011), Daniel Kahneman traz uma compilação de décadas de evidências sobre vieses da cognição.

9 BAZERMAN, Max; LOEWENSTEIN, George; MOORE, Don. Why good accountants do bad audits. Harvard Business Review, Cambridge, v. 80, p. 96-103, nov. 2002.

10 Seu prêmio foi dividido com Vernon L. Smith.

11 SIMON, H. A behavioral model of rational choice. The Quarterly Journal of Economics, Cambridge, v. 69, n. 1, p. 99-118, fev. 1955.

12 De uma forma mais técnica, o autor refere-se a um neologismo: "satisficing", que corresponde à justaposição entre satisfy e suffice, de forma a indicar que se trata de um conceito diferente e mais exigente do que a forma como o termo satisfação é usado no senso comum. 
os outros ${ }^{13}$. Assim, temos duas motivações básicas que entram em conflito, uma que nos diz para maximizar os nossos lucros pessoais, o que às vezes implica agir de forma desonesta, e a outra, que pretende manter uma boa autoimagem, uma imagem de alguém que é honesto e que merece respeito dos outros. Por essa perspectiva, a magnitude da desonestidade observada na sociedade deve-se a pessoas que se consideram honestas e que se convencem de que estão cometendo desvios pequenos e triviais (como explicado adiante). É importante notar que as pessoas, de forma geral, têm uma motivação intrínseca para a honestidade ${ }^{14}$. Apenas uma percentagem muito reduzida da população tem a motivação explícita de agir de forma desonesta ${ }^{15}$.

Conhecendo quais os fatores relevantes que contribuem para o comportamento desonesto e sabendo como estes operam, podemos realizar sutis alterações (nudges) no contexto da decisão de forma a facilitar os comportamentos desejados (honestos) e dificultar os comportamentos indesejados (desonestos).

Neste artigo iremos analisar os principais fatores psicológicos e contextuais que motivam o comportamento desonesto. Esses fatores estão divididos em três grupos (Figura 1): os fatores cognitivos (a forma como a nossa arquitetura mental funciona), contextuais (atributos do contexto que facilitam a ocorrência de atos desonestos) e sociais (a forma como os comportamentos dos outros e as interações sociais nos influenciam). Os nudges, principal elemento prático da ciência comportamental, são, então, intervenções aplicadas ao indivíduo, no momento de sua tomada de decisão, que alteram a maneira como ele responde aos fatores discutidos abaixo. O nudge influi no processo de decisão tendo em conta os elementos do contexto e tem o poder de reduzir, significativamente, certos vieses cognitivos, como discutido em seguida.

Figura 1: sumário dos principais fatores que contribuem para comportamentos desonestos divididos em três categorias: cognitivos, contextuais e sociais

\begin{tabular}{|l|l|l|l|}
\hline - dissonância cognitiva \\
- racionalização/justificação \\
- distância psicológica \\
- necessidade de manter uma \\
autoimagem positiva \\
- o risco das pequenas infrações \\
- licença moral (moral licensing) \\
- depleção/esgotamento do ego \\
(ego-depletion) \\
- controle/autoregulação
\end{tabular}

13 MAZAR, Nina; AMIR, On; ARIELY, Dan. The dishonesty of honest people: a theory of self-concept maintenance. Journal of Marketing Research, Chicago, v. 45, n. 6, p. 633-644, dez. 2008.

14 AQUINO, Karl; REED II, Americus. The self-importance of moral identity. Journal of Personality and Social Psychology, Washington, v. 83, n. 6, p. 1423-1440, dez. 2002.

15 HARE, Robert. Psychopathy: a clinical and forensic overview. Psychiatric Clinics of North America, Amsterdam, v. 29, n. 3, p. 709-724, set. 2006. 


\section{UMA BÚSSOLA MORAL QUEBRADA: FATORES COGNITIVOS}

Nesta seção vamos explorar os mecanismos psicológicos que impactam o julgamento e a tomada de decisão.

Dan Ariely e colegas descrevem, num conjunto de estudos clássicos (e no seu livro intitulado $A$ mais pura verdade sobre desonestidade ${ }^{16}$ ), que serviram de fundamento para investigar muitos dos fenômenos psicológicos da desonestidade, um dos fatores cognitivos com maior impacto em situações de dilemas éticos: a necessidade de manter uma autoimagem positiva. Nesses estudos, os pesquisadores pediam a alunos universitários para resolver puzzles matemáticos. Os participantes eram instruídos a marcar o par de números que somados dão 10 (e.g. $4.81+5.19$ ) em cada puzzle (Figura 2). Para realizar essa tarefa, tinham 5 minutos, e, por cada puzそle correto, receberiam 50 cents. Terminado o tempo, cada participante entregava os seus purzles aos pesquisadores que, por sua vez, contavam o número de acertos e pagavam aos participantes de acordo com o número acertos. Nessa condição (que vamos chamar condição de controle), os participantes acertaram, em média, 4 puzzles. Esse valor foi importante, pois serviu como parâmetro para que diversas hipóteses sobre comportamento desonesto foram testadas e seus resultados comparados com o do grupo de controle.

Figura 2: matrizes matemáticas (ARIELY, 2012, p. 18)

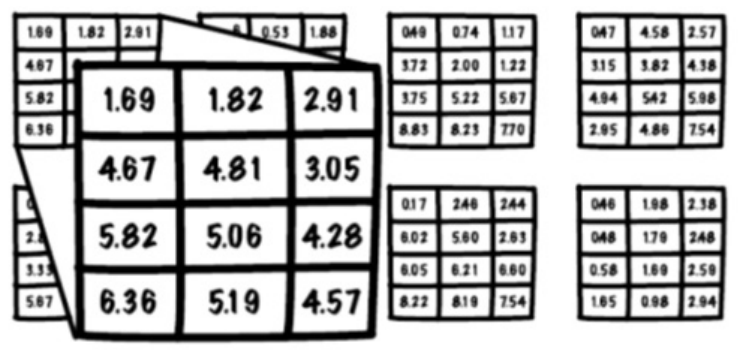

Para testar o nível de desonestidade dos participantes, Ariely e colegas criaram uma condição em que era dada a oportunidade aos participantes de agirem de forma desonesta. Nessa condição (a que vamos chamar a condição-trituradora), em vez de entregarem a matriz com os puzそles aos pesquisadores (para verificarem o número de puzzles resolvidos), os participantes eram solicitados a somar o número de acertos individualmente (sem a presença dos pesquisadores) e, em seguida, triturar as matrizes numa máquina localizada ao fundo da sala. Com a oportunidade de trapacear e sem o perigo de serem descobertos, os participantes relataram ter acertado, em média, 6 questões, duas a mais do que no grupo de controle. Isto sugere que os participantes agiram de uma forma desonesta, mas numa magnitude muito mais baixa do que o possível, de forma a poderem sustentar uma autoimagem positiva, apesar do seu comportamento desonesto. Esse aumento de desonestidade não se deveu ao fato de algumas pessoas terem relatado muito mais, mas sim ao fato de muitas pessoas terem relatado, apenas, um pouco mais do que na realidade acertaram ${ }^{17}$.

Diante dos resultados da condição-trituradora, diversos estudos de follow-up, cada qual com pequenas alterações em relação ao original, foram realizados para testar premissas da teoria econômica tradicional. Por exemplo, em um deles, testou-se se o pagamento recebido por cada puz:le resolvido $(0.50 \$, 1 \$, 2 \$$ ou 5 ), que afetava a incidência e a magnitude do comportamento desonesto. Os resultados revelaram que as pessoas não foram sensíveis aos aumentos no retorno do ato desonesto, continuando a relatar que resolveram, em média, mais dois puzzles, contrariamente ao que preveem os modelos racionais (mais desonestidade para mais benefícios). Tendo em vista os diversos experimentos realizados, os resultados convergem para uma conclusão sobre a psicologia da desonestidade: quando lidamos com situações que envolvam a possi-

16 ARIELY, Dan. A mais pura verdade sobre a desonestidade. Rio de Janeiro: Elsevier, 2012.

17 De acordo com Ariely, em relação ao número de quase 40 mil pessoas que participaram do experimento da matriz em suas diversas variações, aproximadamente 28 mil (ou 70\%) foram um pouco desonestas, ao passo que 20 (ou 0,05\%) pessoas foram extremamente desonestas. 
bilidade de agir desonestamente, mesmo as pessoas mais honestas podem agir de forma desonesta. Nesse tipo de situações, ativa-se um conjunto de mecanismos psicológicos que permite às pessoas conciliar o que a princípio é inconciliável: agir desonestamente e, simultaneamente, manter uma autoimagem positiva de elas próprias.

As pessoas, internamente, traçam um referencial que distingue e separa o que é moralmente aceitável do que não é aceitável para elas. Quando o indivíduo percebe que ultrapassou o seu referencial moral interno, entra num estado de conflito interno. Esse estado de desconforto e de conflito interno, causado pela discrepância entre o comportamento desonesto das pessoas e a sua motivação de se verem como moralmente íntegras, chama-se dissonância ética ${ }^{18}$. Esse referencial é flexível e extremamente sensível à situação, podendo ser ajustado à medida que pequenos atos desonestos são cometidos. Há dois tipos de dissonâncias éticas: 1) dissonância antecipada (no momento em que o indivíduo está considerando realizar o ato) e 2) dissonância experienciada (após o ato) ${ }^{19}$. Mas seja qual for o momento da dissonância, há mecanismos cognitivos que nos permitem lidar com esse desconforto interno e com a culpa.

Em resposta a situações de dissonância ética, adotamos um conjunto de mecanismos cognitivos de racionalização e justificação, com o objetivo de restaurar a nossa autoimagem moralmente íntegra ${ }^{20}$. Um desses mecanismos é a racionalização motivada. ${ }^{21} \mathrm{~A}$ racionalização motivada consiste na reinterpretação das nossas ações ou do contexto, de forma a ficarem mais em sintonia com os nossos valores morais e autoimagem. A racionalização motivada de um ato desonesto pode ocorrer de diferentes formas: pode-se justificar uma transação corrupta reinterpretando-a como sendo uma reparação de uma injustiça anterior, uma ação altruísta indireta ou porque não se está a prejudicar ninguém diretamente.

Algumas situações típicas envolvendo atos de corrupção ilustram esse mecanismo de racionalização. Por exemplo, policiais justificam propinas recebidas de motoristas que querem evitar uma infração com base em baixos salários. Entretanto, estudos revelam que alterar apenas um elemento de contexto, nesse caso, aumentar os salários, não diminui necessariamente a atividade corrupta ${ }^{22}$. $\mathrm{O}$ uso de nudges $-\mathrm{em}$ momentos-chave na rotina dos policiais, como lembretes do código de honra da corporação em momentos de abordagem de trânsito, poderia levar alguns a mudar de decisão quanto a solicitar propinas.

No mesmo sentido, ser usufrutuário de um trust que tem cinco milhões de dólares suspeitos soa menos repugnante do que ser dono de uma conta pessoal com cinco milhões de dólares. Abstrações, como trusts, facilitam a racionalização motivada de quem está sendo desonesto. Nesse sentido, intervenções que chamem a atenção de forma explícita para a equivalência dessas abstrações e o montante correspondente em dinheiro ou que classifiquem, de forma inequívoca, o ato desonesto como tal, podem dificultar ou prevenir racionalizações. O nosso poder criativo nesse campo é imenso, e, quanto mais ambíguas forem as regras, mais espaço há para este tipo de justificações ${ }^{23}$.

18 MAZAR, Nina; ARIELY, Dan. Dishonesty in everyday life and its policy implications. Journal of Public Policy \& Marketing, Chicago, v. 25, n. 1, p. 117-126, mar. 2006.

19 BARKAN, Rachel; AYAL, Shahar; ARIELY, Dan. Ethical dissonance. justifications, and moral behavior. Current Opinion in Psychology, New York, v. 6, p. 157-161, dec. 2015.

20 BARKAN, Rachel et al. The pot calling the kettle black: distancing response to ethical dissonance. Journal of Experimental Psychology: General, Washington, v. 141, n. 4, p. 757-773, nov. 2012.

21 KUNDA, Ziva. The case for motivated reasoning. Psychological Bulletin, Washington, v. 108, n. 3, p. 480-498, nov. 1990.

22 O exemplo dos policiais e um caso real no Afeganistão apresentado no artigo do jornal inglês The Guardian que mostra como a percepção de injustiça causada pelos baixos salários cria uma justificativa para o ato corrupto. Entretanto, estudo feito com policiais em Gana que receberam um aumento salarial indica que eles continuam solicitando propina mesmo após o aumento. SIEFF, Kevin. Low pay and one minor promotion for the most honest man in Afghanistan. The Washington Post, 31 Jan 2014. Disponível em: <https://www.theguardian.com/world/2014/jan/31/afghanistan-corruption-honest-police-officer> e FOLTZ, Jeremy D.; OPOKU-AGYEMANG, Kweku A. Do higher salaries lower petty corruption? A policy experiment on West Africa's highways. 2015. Disponível em: <http://cega.berkeley.edu/assets/miscellaneous_files/Opoku-Agyemang_WGAPE_2015.pdf>.

23 GINO, Francesca; ARIELY, Dan. The dark side of creativity: original thinkers can be more dishonest. Journal of Personality and Social Psychology, v. 102, n. 3, p. 445-459, nov. 2012. 
Além da necessidade de manter uma autoimagem positiva, existem outros fatores cognitivos igualmente relevantes para o comportamento desonesto.

O primeiro diz respeito ao fenômeno cognitivo da distância psicológica. A distância psicológica aumenta a flexibilidade com que se consegue reinterpretar atos desonestos como honestos. Assim, quando existe uma distância psicológica relativamente ao dinheiro ${ }^{24}$ (como no exemplo do usufrutuário de um trust, ou da latinha de refrigerante), os comportamentos desonestos tendem a ocorrer mais. Imagine a diferença entre pegar uma caneta esferográfica (de dois reais) da mala de um amigo e pegar dois reais da mala do seu amigo para comprar uma esferográfica para si. Apesar do valor monetário ser igual nos dois casos, psicologicamente, a primeira opção é sentida como muito mais próxima, o que, por sua vez, causa uma dissonância menor e é mais facilmente justificada.

No mesmo sentido, voltando aos puzそles acima mencionado de Ariely e colegas, demonstrou-se, em uma das condições, que introduzir um meio intermediário no processo de pagamento (ser pago em tokens que são posteriormente convertidos em dinheiro) aumenta a incidência de comportamentos desonestos. Os tokens, nesse caso, servem como uma forma de o participante se distanciar do ato desonesto.

Para além da questão da distância psicológica, quando cometemos um ato desonesto, podemos sentir a necessidade de compensá-lo com um ato honesto ou pró-social, fenômeno chamado ajuste ou balanceamento moral (moral balancing $g^{25}$ ). Por exemplo, as pessoas tendem a desinfetar mais as suas mãos depois de transcreverem uma história que narre comportamentos desonestos ${ }^{26}$, numa tentativa inconsciente de "se limparem" do ato desonesto (fenômeno chamado moral cleansing).

Noutro estudo ${ }^{27}$, pediu-se aos participantes para copiarem uma lista de traços positivos (e.g. generoso, justo), negativos (e.g. desleal, egoísta) ou objetos inanimados (ex.: livro, chaves). Depois de copiarem a lista de palavras, os participantes escreveram uma história curta sobre eles próprios, que incluía todas as palavras que tinham copiado. Ao final do experimento, perguntaram-se aos participantes se queriam fazer uma pequena doação (até \$10) e se pediu para escreverem o nome da instituição para a qual desejariam doar e o montante da doação. Verificou-se que os participantes que copiaram a lista de traços positivos doaram, em média, $\$ 1,07$, enquanto os participantes na condição de traços negativos doaram, em média, \$5,30. Esses resultados sugerem que salientar uma identidade moral positiva "dá licença" às pessoas para serem, nesse caso, não propriamente desonestas, mas menos pró-sociais do que as pessoas cujos aspetos negativos da sua identidade moral estivessem bem presentes.

Esse fenômeno do balanceamento moral, infelizmente, também funciona ao contrário: um ato moralmente positivo (e.g. fazer uma doação a uma instituição de caridade) pode criar um sentimento de licença moral para fazer algo negativo seguidamente, como agir de forma desonesta (moral self-licencing) ${ }^{28}$.

24 MAZAR, Nina; ARIELY, Dan. Dishonesty in everyday life and its policy implications. Journal of Public Policy \& Marketing, Chicago, v. 25, n. 1, p. 117-126, mar. 2006.

25 SACHDEVA, Sonya; ILIEV, Rumen; MEDIN, Douglas. Sinning saints and saintly sinners: the paradox of moral self-regulation. Psychological Science, Washington, v. 20, n. 4, p. 523-528, abr. 2009.

26 ZHONG, Chen-Bo; LILJENQUIST, Katie. Washing away your sins: threatened morality and physical cleansing. Science, Washington, v. 313, n. 5792, p. 1451-1452, set. 2006.

27 SACHDEVA, Sonya; ILIEV, Rumen; MEDIN, Douglas. Sinning saints and saintly sinners: the paradox of moral self-regulation. Psychological Science, Washington, v. 20, n. 4, p. 523-528, abr. 2009.

28 HOUSER, Daniel; VETTER, Stefan; WINTER, Joachim. Fairness and cheating. European Economic Review, Amsterdam, v. 56, n. 8, p. 1645-1655, nov. 2012.

PLONER, Matteo; REGNER, Tobias. Self-image and moral balancing: an experimental analysis. Journal of Economic Behaviors and Organization, Amsterdam, v. 93, p. 374-383, set. 2013.

CARLSMITH, J. Merrill; GROSS, Alan. Some effects of guilt on compliance. Journal of Personality and Social Psychology, Washington, v. 11, n. 3, p. 232-239, mar. 1969

GNEEZY, Uri; IMAS, Alex; MADARÁSZ, Kristóf. Conscience accounting: emotion dynamics and social behavior. Management Science, Maryland, v. 60, n. 11, p. 2645-2658, ago. 2014.

KALANTHROFF, Eyal; ASLAN, Chen; DAR, Reuven. Washing away your sins will set your mind free: physical cleansing modulates the effect of threatened morality on executive control. Cognition and Emotion, London, v. 31, n. 1, p. 185-192, 2017. 
Adicionalmente, a forma como as pessoas lidam com situações de tentação, e as suas capacidades de autocontrole perante as mesmas, pode ter um impacto significativo no comportamento. Funcionários do setor público e privado lidam, sistematicamente, com tentações, tais como ofertas de propinas por terceiros, possibilidade de abuso de poder etc. Nesse contexto, o fenômeno de ego-depletion tem um papel crítico. Esse fenômeno refere-se a um estado mental debilitado em termos de recursos cognitivos devido a fatores como o cansaço físico ou mental, a falta de tempo ou a ansiedade. Os recursos cognitivos são importantes para exercer o autocontrole necessário para lidar com essas situações de tentação, e, na falta destes, sucumbimos a motivações egoístas, favorecendo uma gratificação imediata ${ }^{29}$.

Num estudo ${ }^{30}$, os participantes foram convidados a escrever um pequeno ensaio não podendo usar palavras que tivessem as letras "a" ou " $\mathrm{n}$ " (condição depletion) ou as letras " $\mathrm{x}$ " ou " $\mathrm{z}$ " (condição no-depletion). A ideia é que escrever sem as letras "a" ou " $n$ " é uma tarefa que demanda muito mais recursos cognitivos do que sem as letras " $x$ " ou " $z$ ". Depois dessa tarefa, os participantes tiveram de resolver os mesmos puzzles matemáticos dos estudos referidos anteriormente. Cada puzそle resolvido valia $\$ 0,25$. Numa das condições (experimenter-scored), os participantes entregavam a folha de respostas ao experimentador, que lhes pagava de acordo com o número de puzzles resolvidos. $\mathrm{Na}$ outra condição experimental (self-scored), os participantes contavam quantos puzzles tinham resolvido, e eram colocados dois envelopes sobre uma mesa, antes da chegada dos participantes: um tinha 20 moedas de $\$ 0,25$ e o outro estava vazio. Os participantes tinham de deixar $\$ 0,25$ por cada puzそle que tivessem resolvido, e transferir os restantes $\$ 0,25$ para o envelope vazio, deixando-o sobre a mesa. Os resultados mostraram que os participantes na condição no-depletion "afirmaram" ter resolvido mais $25 \%$ de puzzles quando eram eles próprios a verificar o seu desempenho do que quando era o experimentador. Em contraste, na condição depletion, essa diferença subiu para 104\%, o que sugere um aumento da desonestidade quando os recursos cognitivos dos participantes eram baixos.

Assim, é importante evitar que funcionários tomem decisões que envolvam a possibilidade de agir desonestamente e que demandem autocontrole em estado de forte ego-depletion, como após horas sem intervalo ou na parte final do expediente.

A literatura, também, indica que antecipar situações de tentação é uma forma eficaz de treinamento e permite às pessoas deliberar sobre as ações honestas específicas a tomar, tornando-as mais preparadas para agir de forma honesta quando uma situação semelhante acontecer na realidade ${ }^{31}$. Algumas categorias de funcionários públicos recebem, por exemplo, treinamento sobre como identificar uma situação de corrupção quando operam em setores onde há incidência significativa de atividade corrupta. ${ }^{32}$ Ainda que o treinamento possa ser esquecido com o tempo, a exposição a situações baseadas em fatos ajuda os funcionários a racionar, num espaço protegido, e decidir que passos deveriam tomar frente ao problema. Quando e se eles vierem a ter contato com tal situação no futuro, a chance de tomarem a melhor decisão e maior.

Finalmente, as pessoas, também, podem interpretar positivamente os seus atos desonestos, focando-se nos benefícios que esses comportamentos têm para outros, e não nos seus ganhos pessoais ${ }^{33}$. Por exemplo,

ZHONG, Chen-Bo; LILJENQUIST, Katie. Washing away your sins: threatened morality and physical cleansing. Science, Washington, v. 313, n. 5792, p. 1451-1452, set. 2006.

29 Para mais acerca da importância da gratificação imediata ver: BAZERMAN, Max; TENBRUNSEL, Ann. Blind spots: why we fail to do what's right and what to do about it. Princeton: Princeton University Press, 2011.

30 MEAD, Nicole et al. Too tired to tell the truth: self-control resource depletion and dishonesty. Journal of Experimental Social Psychology, Amsterdam, v. 45, n. 3, p. 594-597, maio 2009.

31 SHELDON, Oliver; FISHBACH, Ayelet. Anticipating and resisting the temptation to behave unethically. Personality and Social Psychology Bulletin, California, v. 41, n. 7, p. 962-975, jul. 2015.

32 Por exemplo, diplomatas e pessoal de cooperação internacional em muitos países passam por treinamento presencial ou virtual obrigatório antes de assumir um posto de trabalho. Esses treinamentos muitas vezes incluem vivenciar situações fictícias elaboradas a partir de casos de corrupção reais envolvendo o órgão público no passado (OECD, 2017).

33 AYAL, Shahar; GINO, Francesca. Honest rationales for dishonest behavior. In: MIKULINCER, Mario; SHAVER, Philip (Org.). The social psychology of morality: exploring the causes of good and evil. Washington: American Psychological Association, 2012. p. 149-166. 
em um dos follow-ups dos estudos com puzzles matemáticos já citado, Gino, Ayal e Ariely $y^{34}$ pediram aos participantes para solucionar os puzzles individualmente, em pares ou em grupos de três pessoas. Os resultados indicaram que os participantes reportaram mais puzzles resolvidos quando em grupos de três pessoas, uma vez que a situação podia ser reinterpretada como "ajudando os outros" 35 . No caso da corrupção, um gestor pode resguardar-se, mentalmente, da reprovabilidade de um ato corrupto em razão dos benefícios que este traz para a sua organização ou para um grupo de colaboradores. Estudos etnográficos da corrupção mostram como pressões de grupo ou família podem ser fatores poderosos para que o indivíduo cometa atos de corrupção que não o beneficiam individualmente, mas sim a alguém do grupo, e encontrem justificativas morais para seus atos. ${ }^{36}$

\section{AJUDANDO O INDIVÍDUO HONESTO A CONTINUAR HONESTO: FATORES CONTEXTUAIS}

O contexto em que o indivíduo está inserido pode ter um papel significativo no seu comportamento. Conforme ressaltam Thaler e Sunstein no seminal livro Nudge $e^{37}$, uma contribuição dos estudos comportamentais para as políticas públicas é a ênfase nos fatores contextuais. Nas palavras dos autores: “[...] detalhes pequenos e aparentemente insignificantes podem ter grande impacto no comportamento das pessoas. Uma boa regra de ouro (rule of thumb) é assumir que tudo importa." ${ }^{38}$. Nesta seção, vamos explorar alguns dos fatores contextuais com impactos no comportamento desonesto, desde mensagens explícitas (como códigos de ética e regulamentos) e implícitas (o que as outras pessoas fazem de fato) que o contexto transmite, às suas inconsistências e ambiguidades.

Como já mencionado acima, uma solução tradicionalmente proposta no contexto do combate à corrupção, é alterar o contexto aumentando o nível de controle e fiscalização. No entanto, os mecanismos de controle têm o risco de diminuir a motivação intrínseca das pessoas para agir de forma íntegra ${ }^{39}$. As intervenções baseadas em fiscalização e penalização sinalizam desconfiança e dão a indicação de que a norma social (o que os outros fazem) é agir, de forma desonesta, o que, por sua vez, pode levar a ainda mais comportamentos desonestos. Uma possível forma de diminuir a desconfiança, quando se implementa um sistema de controle, é de ter uma entidade externa fazendo a fiscalização e não alguém interno (da organização ou da equipe).

Há outros fatores contextuais e não relacionados a um controle direto que afetam a forma como interpretamos a informação ou a situação e a forma como nos comportamos seguidamente. Em primeiro lugar, em contextos de ambiguidade (em que os riscos e consequências do ato desonesto são ambíguos ou quando o alvo afetado ou a vítima não são facilmente identificáveis), é mais provável que ocorra a racionalização motivada ${ }^{40}$ e que os chamados self-serving biases entrem em ação, distorcendo a interpretação das situações e

34 GINO, Francesca; AYAL, Shahar; ARIELY, Dan. Self-serving altruism? The lure of unethical actions that benefit others. Journal of Economic Behavior \& Organization, Amsterdam, v. 93, p. 285-292, set. 2013.

35 AYAL, Shahar; GINO, Francesca. Honest rationales for dishonest behavior. In: MIKULINCER, Mario; SHAVER, Philip (Org.). The social psychology of morality: exploring the causes of good and evil. Washington: American Psychological Association, 2012. p. $149-166$.

36 Anders (2005) estudou o caso das obrigações familiares no Malauí (por exemplo, empregar familiares quando um indivíduo alcança um cargo público). Estes atos são considerados obrigações morais e não atos corruptos.

37 THALER, Richard; SUNSTEIN, Cass. Nudge: como melhorar as decisões sobre saúde, dinheiro e felicidade. Lisboa: Academia do Livro, 2009.

38 THALER, Richard; SUNSTEIN, Cass. Nudge: como melhorar as decisões sobre saúde, dinheiro e felicidade. Lisboa: Academia do Livro, 2009. p. 16.

39 LAMBSDORFF, Johann. Preventing corruption by promoting trust: insights from behavioral science. Passauer Diskussionspapiere: Volkswirtschaftliche Reihe, Passau, v. 69, n. 15, p. 1-16, 2015.

SCHULZE, Günther; FRANK, Björn. Deterrence versus intrinsic motivation: experimental evidence on the determinants of corruptibility. Economics of Governance, Cham, v. 4, n. 2, p. 143-160, ago. 2003.

40 HSEE, Christopher. Elastic justification: how tempting but task-irrelevant factors influence decisions. Organizational Behavior 
contextos de acordo com os objetivos egoístas do indivíduo.

Em segundo, quando as consequências de uma ação são tardias e não imediatas, o comportamento desonesto é mais provável. Isto ocorre porque temos a tendência a dar mais peso a benefícios e custos imedia-

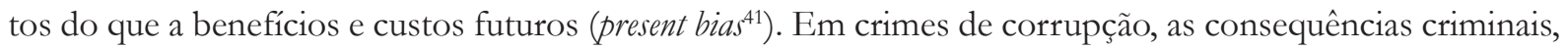
quando acontecem, são concretizadas muito tempo depois do ato corrupto, enquanto os benefícios desse ato são muitas vezes imediatos (em forma de benefícios financeiros, como propina, ou favor).

Em terceiro, nos casos em que a vítima do ato desonesto não é fácil de identificar, a probabilidade de ocorrerem comportamentos desonestos aumenta ${ }^{42}$. A corrupção consiste, muitas vezes, em cadeias complexas de intermediários que tornam os danos menos visíveis e imediatos. Nas situações em que é o "Estado" ou a "população como um todo" os prejudicados, trata-se de um caso de vítima indireta ou social, pois ambas as entidades (Estado e população) são muito abstratas e o prejuízo da corrupção, por sua vez, é difícil de mensurar. Um exemplo dessa complexidade são os efeitos que a corrupção da classe política tem nos serviços públicos. Ainda que os danos existam, estabelecer uma relação causal direta entre um ato de corrupção específico e a degradação de um serviço público é bastante difícil. ${ }^{43}$

Mas como podemos alterar o contexto de forma a influenciar positivamente o comportamento das pessoas? Uma forma é implementar lembretes morais em momentos-chave da tomada de decisão, de forma a conduzi-las momentaneamente a um mindset ético. A ideia é que, lembradas de sua honestidade, as pessoas vão reforçar, momentaneamente, sua autoimagem íntegra, o que, por sua vez, tornará mais severa a dissonância cognitiva entre suas ações desonestas e autoimagem. Em particular, estes lembretes podem ser implementados em lugares onde o comportamento ocorre, de modo a que possam ser vistos oportunamente, isto é, antes do ato ocorrer. Uma mensagem como "obrigada pela sua honestidade" pode servir de lembrete moral ${ }^{44}$. É importante ressaltar que os lembretes morais devem ser usados com cautela, porque, quando utilizados com frequência e apresentados sempre da mesma forma, podem deixar de ter efeito devido à habituação. Assim, é importante personalizar e incluir, constantemente, detalhes novos nos lembretes.

Imaginemos um código de conduta que os funcionários públicos têm que assinar. Primeiramente, esses códigos são consultados (quando o são) e assinados uma única vez, no momento em que a pessoa toma posse da função. Essa atividade tem muito pouco impacto no comportamento porque é facilmente esquecida e a atividade do dia a dia não requer a sua consulta regular. Uma possível alteração implicaria pedir aos funcionários que consultassem o código de conduta ética e assinassem uma declaração de honra a cada novo contrato público em que o funcionário fosse participar (antes do mesmo ser realizado). Nesse exemplo, para evitar habituação ao conteúdo da declaração e ao ato de assinar (que quando repetido muitas vezes, pode

and Human Decision Processes, Amsterdam, v. 62, n. 3, p. 330-337, jun. 1995.

HSEE, Christopher. Elastic justification: how unjustifiable factors influence judgments. Organizational Behavior and Human Decision Processes, Amsterdam, v. 66, n. 1, p. 122-129, abr. 1996.

41 O'DONOGHUE, Ted; RABIN, Matthew. Doing it now or later. American Economic Review, Pittsburgh, v. 89, n. 1, p. 103-124, mar. 1999.

42 FALK, Armin; SZECH, Nora. Organizations, diffused pivotality and immoral outcomes. 2013. Disponível em: < https://polit.econ.kit. edu/downloads/papers/Falk_Szech_WP_2_Pivotality_Fal_Szech_DP-2.pdf>. Acesso em: 2 maio 2018.

HAMMAN, John; LOEWENSTEIN, George; WEBER, Roberto. Self-interest through delegation: an additional rationale for the principal-agent relationship. American Economic Review, Tennessee, v. 100, n. 4, p. 1826-1846, set. 2010.

43 Um exemplo de investigação que estabeleceu relação causal entre corrupção e degradação de serviços públicos envolve o colapso da fábrica de roupas Rana em Bangladesh em 2013, em que faleceram centenas de empregados. Uma investigação comprovou que houve corrupção na aprovação de uso do edifício onde operava a fábrica, que não respeitava normas de segurança e, ainda assim, continuava funcionando. RANA Plaza owner jailed for three years over corruption. 29 August 2017. Disponível em: < https:// www.aljazeera.com/news/2017/08/rana-plaza-owner-jailed-years-corruption-170829161742916.html>.

44 BURSZTYN, Leonardo et al. Moral incentives in credit card debt repayment: evidence from a field experiment. The National Bureau of Economic Research Working Paper, n. 21611, Nov. 2017.

MAZAR, Nina; ARIELY, Dan. Dishonesty in everyday life and its policy implications. Journal of Public Policy \& Marketing, Chicago, v. 25, n. 1, p. 117-126, mar. 2006.

PRUCKNER, Gerald; SAUSGRUBER, Rupert. Honesty on the streets: a field study on newspaper purchasing. Journal of the European Economic Association, New Jersey, v. 11, n. 3, p. 661-679, jun. 2013. 
ficar automático), o texto dessa declaração deveria variar ligeiramente em cada contrato. Essa declaração ativaria standards morais internos na altura crítica em que a pessoa fosse confrontada com um eventual momento de tentação de agir desonestamente.

Mazar, Amir, e Ariely ${ }^{45}$, utilizaram um lembrete diferente num estudo experimental para conduzir os participantes a um mindset moral. Esse lembrete consistiu em pedir aos participantes para se recordarem e escreverem os 10 Mandamentos da Bíblia (versus os últimos 10 livros que leram, na condição de controle do estudo). Ao terem que pensar nos 10 Mandamentos (independentemente da sua religião, de acreditarem em Deus, ou de se recordarem de fato dos Mandamentos), os padrões morais dos participantes ficaram mais salientes e, por isso, os participantes tenderam a agir mais honestamente. Em seguida, os participantes resolveram pu₹そles matemáticos semelhantes aos descritos anteriormente. Na condição trituradora (em que a prova do número de pu₹そles corretos era destruída pelo próprio participante), verificou-se que, depois de se lembrarem dos 10 livros, os participantes relataram, em média, 4.2 pu₹zles, enquanto os participantes que tiveram de escrever os 10 Mandamentos relataram, em média, 2.8 puzzles. Tendo por base esse resultado, os pesquisadores concluíram que, ativando valores morais, diminui-se a incidência de comportamentos desonestos.

\section{SOCIALMENTE DESONESTO: FATORES SOCIAIS}

O comportamento desonesto, também, pode ser influenciado pela interação com outras pessoas. O que a maioria das outras pessoas está fazendo (prova social) influencia, fortemente, o nosso comportamento e contribuem para a definição de nossos padrões morais comportamentais ${ }^{46}$, especialmente em situações de incerteza. Essa influência, por sua vez, é maior quanto mais nos identificamos com essas pessoas ${ }^{47}$. Assim, se outras pessoas à volta agirem de forma desonesta, e se esses outros forem do in-group (pessoas com quem compartilhamos características, tais como a mesma profissão ou cidade de residência), o risco de contágio do comportamento desonesto aumenta. Assim, um médico tem maior probabilidade em praticar superfaturamento se outros médicos do mesmo departamento o fizerem.

Além de modelar diretamente o comportamento de acordo com o comportamento dos outros, há outros fatores sociais que podem contribuir para que as pessoas ajam de forma desonesta. Um desses fatores é a tendência de agir de forma desonesta em prol dos outros. Isso acontece quando o comportamento desonesto beneficia alguém, sendo esse efeito, uma vez mais, mais forte quanto mais próxima for a pessoa beneficiada. Como exemplo, imaginemos uma situação comum: de uma enfermeira que trabalha num hospital público onde a lista de espera para consultas é extremamente longa. Uma amiga da enfermeira precisa de uma consulta e a enfermeira vê-se numa situação em que pode ajudar facilmente esta amiga a furar a longa fila de espera. Nesse caso, o fato de ser uma amiga a pedir esse favor, e não um desconhecido, aumenta, de forma significativa, a probabilidade de ocorrência do ato desonesto, o que configura um caso típico de altruistic cheating ${ }^{48}$.

Adicionalmente, há investigação que mostra que as pessoas são mais desonestas em situações de desigualdade de tratamento ${ }^{49}$, isto é, se a pessoa acha que está sendo injustiçada ou que a outra parte está

45 MAZAR, Nina; AMIR, On; ARIELY, Dan. The dishonesty of honest people: a theory of self-concept maintenance. Journal of Marketing Research, Chicago, v. 45, n. 6, p. 633-644, dez. 2008.

46 MOORE, Celia; GINO, Francesca. Ethically adrift: how others pull our moral compass from true north, and how we can fix it. Research in Organizational Behavior, Amsterdam, v. 33, p. 53-77, 2013.

47 GINO, Francesca; AYAL, Shahar; ARIELY, Dan. Contagion and differentiation in unethical behavior: the effect of one bad apple on the barrel. Psychological Science, California, v. 20, n. 3, p. 393-398, mar. 2009.

48 De notar, no entanto, que há questões culturais que guiam os nossos comportamentos na interação com os outros e que nos podem levar a agir de forma desonesta devido a práticas altamente difusas na população e aceites por toda gente.

49 GINO, Francesca; PIERCE, Lamar. Dishonesty in the name of equity. Psychological Science, Washington, v. 20, n. 3, p. 1153- 
tendo maiores benefícios do que o devido em determinado contexto. Além da desigualdade, as situações de reciprocidade ${ }^{50,51}$ também podem ter efeitos potencialmente negativos para a integridade. O ser humano, em todas as culturas, é altamente sensível à reciprocidade, de forma que, quando recebemos um benefício, seja um pequeno presente ou um favor, sentimos uma forte pressão para retribuir. Essa força psicológica é um fator-chave na criação e manutenção da corrupção, uma vez que a corrupção baseia-se num acordo entre pelo menos dois parceiros - o corruptor ativo, que fornece o bem em questão, e o corrupto passivo, que aceita a transação corrupta. Esse acordo, por sua vez, tende a caracterizar-se por uma elevada incerteza, o que reforça a exigência normas de reciprocidade que criem confiança entre os agentes envolvidos ${ }^{52}$.

Aumentar a transparência é considerado um meio eficaz para reduzir a corrupção. A ideia é que, quanto mais mecanismos de transparência maior o risco de se descubram desvios e, consequentemente, menos pessoas estarão dispostas a cometer desvios. No entanto, a literatura comportamental demonstra que, em diversas situações, a transparência pode ter efeitos inversos do esperado.

Um mecanismo de transparência é a declaração dos conflitos de interesse (por exemplo, de um médico pode declarar para o paciente que está diagnosticando, que tem benefícios diretos na execução de determinada cirurgia) pode ter o efeito oposto, isto é, pode legitimar ações desonestas ${ }^{53}$. O investigador americano George Loewenstein e os seus colaboradores mostraram que, a seguir a uma declaração de conflitos de interesses, as pessoas sentem-se mais à vontade para agir, abertamente, de forma enviesada porque sentem que não estão a esconder nada ${ }^{54}$. A transparência, nesse caso, pode funcionar como absolvição do comportamento desonesto. Simultaneamente, a pessoa a quem o conflito de interesses pode afetar (paciente) interpreta essa divulgação de informação relativamente aos conflitos de interesse como um sinal de confiança da outra parte, levando a uma clara assimetria de circunstâncias.

Nesse sentido, é necessário ficar ciente de que uma governança transparente, com políticas de livre e pleno acesso aos dados, pode ter um efeito oposto ao desejado, se outros mecanismos de accountability precisam ser postos em prática. Portanto, a sociedade civil e a mídia têm um papel importante na salientação de que os atos são indesejados podem ter um papel crucial para que os mecanismos de transparência sejam eficazes.

Por fim, um último fator social relevante é a difusão da responsabilidade ${ }^{55}$. Em situações em que um grupo de pessoas age de forma corrupta em conjunto, há uma desresponsabilização generalizada no grupo, que resulta numa atribuição de menor responsabilidade individual a cada uma das pessoas do grupo. Tendo em vista esse fator social, o conhecido princípio dos "quatro olhos", que consiste em ter mais pessoas envolvidas e criar diversas camadas sucessivas de fiscalização, pode não funcionar tão bem devido à difusão da responsabilidade entre os vários agentes envolvidos.

1160, set. 2009.

50 BOWLES, Samuel; GINTIS, Herbert. Schooling in capitalist America: educational reform and the contradictions of economic life. Chicago: Haymarket Books, 2011.

51 HENRICH, Joseph, et al. "Economic man" in cross-cultural perspective: behavioral experiments in 15 small-scale societies. Behavioral and Brain Sciences, New York, v. 28, n. 6 p. 795-855, dez. 2005.

52 SOUSA, Luís de. Corrupção. Lisboa: Fundação Francisco Manuel dos Santos, 2011.

53 SAH, Sunita; LOEWENSTEIN G.; CAIN, Daylian. The burden of disclosure: increased compliance with distrusted advice. Journal of Personality and Social Psychology, Washington, v. 104, n. 2, p. 289-304, fev. 2013.

54 CAIN, Daylian; LOEWENSTEIN, George; MOORE, Don. The dirt on coming clean: perverse effects of disclosing conflicts of interest. Journal of Legal Studies, Chicago, v. 34, n. 1, p. 1-25, jan. 2005.

CAIN, Daylian; LOEWENSTEIN, George; MOORE, Don. When sunlight fails to disinfect: understanding the perverse effects of disclosing conflicts of interest. Journal of Consumer Research, Chicago, v. 37, n. 5, p. 836-857, fev. 2011.

LOEWENSTEIN, G.; SAH, Sunita; CAIN, Daylian. The unintended consequences of conflict of interest disclosure. The Journal of the American Medical Association, Chicago, v. 307, n. 7, p. 669-670, fev. 2012.

55 SCHIKORA, Jan. Bringing the four-eyes-principle to the lab. 2011. Disponível em:

<https://epub.ub.uni-muenchen.de/12160/1/The4EP_Schikora.pdf>. Acesso em: 10 maio 2018.

WILTERMUTH, Scott. Cheating more when the spoils are split. Organizational Behavior and Human Decision Processes, Amsterdam, v. 115, n. 2, p. 157-168, jul. 2011.

MOORE, Celia; GINO, Francesca. Ethically adrift: how others pull our moral compass from true north, and how we can fix it. Research in Organizational Behavior, Amsterdam, v. 33, p. 53-77, 2013. 
Os exemplos da transparência e da fiscalização mostram que, por diversas vezes, as soluções tradicionalmente empreendidas, por mais intuitivas que pareçam, nem sempre funcionam de forma linear e podem ter efeitos contrários aos previstos devido a mecanismos sociais sutis.

\section{Considerações finais}

Neste artigo, apresentamos diversos fatores cognitivos, contextuais e sociais que, apesar de relevantes para o comportamento desonesto, não costumam ser considerados em abordagens tradicionais. Em específico, afirmamos que as pessoas não são necessariamente racionais, coerentes e previsíveis nas suas decisões, e relativamente insensíveis a análises de custo-benefício em relação às consequências de comportamentos desonestos. Além disto, identificamos como central o conceito de autoimagem e o fato de essa não ser tão condicionada pelo cometimento de atos desonestos como seria de esperar.

Por fim, indicaremos um rol de soluções baseadas em intervenções comportamentais e alterações na arquitetura da decisão, que podem ser implementadas com o objetivo de guiar o comportamento no sentido de mais integridade.

Uma dessas intervenções comportamentais refere-se aos protocolos de conduta e aos códigos de ética. Como vimos, para serem mais eficazes, estes devem ser desenvolvidos tendo por base dois objetivos principais: 1) evitar ambiguidades e 2) e levar à ativação de standards morais internos, especialmente em momentos críticos de decisão. Esses objetivos visam mitigar a nossa tendência natural de racionalizar, reinterpretar e justificar as nossas ações desonestas. Portanto, para mitigar essa tendência, protocolos e guias devem tornar questões cinzentas ou ambíguas em categorias dicotômicas em que os comportamentos são claramente honestos ou desonestos, sem meio termo. Nesse sentido, é importante classificar um rol de comportamentos como desonestas, informar acerca da sua ilegalidade e indicar, com o máximo de detalhamento possível, qual a forma correta de agir. Esses códigos de conduta e protocolos podem, por exemplo, fazer menção aos subornos em formato de presentes, deixando clara a ilegalidade destes e indicando como agir se detectar tal situação (encorajando e guiando o whistleblowing). Os protocolos de conduta, por sua vez, podem prever o engatilhamento (trigger) de alarmes e valores morais, especialmente em momentos críticos, isto é, logo antes da oportunidade do comportamento desonesto. Uma forma de o fazer é pedindo ao agente para se lembrar dos seus deveres éticos (e.g assinar uma declaração de honra) em situações em que exista vulnerabilidade de ser corrompido, e não em momentos inócuos, como é habitualmente feito ${ }^{56}$.

O treinamento ético é outra medida que pode preparar as pessoas para a detecção de irregularidades em si mesmas e nos outros ${ }^{57}$. É importante que as pessoas aprendam a identificar quais são os principais momentos de tentação na sua função dentro da organização, para que se possam simular, em treino, medidas a tomar se e quando essas irregularidades ocorrerem na prática ${ }^{58}$.

Uma outra forma de tornar a pessoa mais consciente do seu próprio processo de decisão consiste em pedir para explicar as decisões tomadas (ex.: pedir ao médico para justificar porque aconselha determinada cirurgia ou equipamento, ou pedir a um funcionário público para justificar determinada compra pública ou

56 SHU, L. et al. Signing at the beginning makes ethics salient and decreases dishonest self-reports in comparison to signing at the end. Proceedings of the National Academy of Sciences of the United States of America, Washington, v. 109, n. 38, p. 15197- 15200, set. 2012. 57 ASHFORTH, Blake; ANAND, Vikas. The normalization of corruption in organizations. Research in Organizational Behavior, Amsterdam, v. 25, p. 1-52, 2003.

58 Prever e antecipar todas as situações de corrupção, em todas as suas formas e especificidades, é muito difícil, senão impossível devido ao fator criatividade. Mas uma organização pode fazer um levantamento das irregularidades mais comuns e preparar os seus funcionários a reagir às mesmas. Uma possível solução, que já tem vindo a ser adoptada, é criar linhas de apoio e conselho para que funcionários possam pedir esclarecimento e conselhos em como agir sem medo de represália. Mas neste caso o alarme moral tem que ser interno ao indivíduo, e esses alarme pode nunca soar devido aos vieses a respeito dos quais falamos neste artigo. 
determinada atribuição de fundos). Isto coloca uma responsabilidade acrescentada no decisor e o torna mais consciente de possíveis vieses cognitivos automáticos que poderão ter conduzido a decisões desonestas.

Finalmente, é importante estar atento para as dinâmicas sociais das organizações. Essas dinâmicas podem estar contribuindo para comportamentos desonestos, tornando-os mais aceitáveis e favorecendo o seu "contágio" entre os colaboradores. Isto é especialmente verdade em situações em que não estão claras as consequências negativas dos comportamentos desonestos e quando o desrespeito às normas éticas ocorre de forma gradual e não-abrupta. Uma forma de frear este "contágio", especialmente em situações em que o comportamento desonesto (ainda) não está completamente difundido na organização, é comunicar às pessoas normas sociais positivas, deixando claro que grande parte das pessoas age de forma honesta, que isso é o normal nos contextos em questão.

Para finalizar, é importante perceber as limitações das intervenções baseadas na ciência comportamental no campo do combate à corrupção e ao comportamento desonesto. Apesar de a aplicação das ciências comportamentais fornecer formas promissoras de alterar comportamentos (porque são fundamentadas em investigação, têm baixo custo e consistirem em alterações sutis, e de fácil implementação, na arquitetura da decisão), essas formas não são suficientes para reduzir drasticamente os níveis de corrupção numa sociedade ou numa dada organização. Por isso, a melhor forma de aplicar a Economia Comportamental é complementando-a com as práticas tradicionais, nomeadamente, integrando intervenções comportamentais nas políticas de conscientização e educação, por um lado, e nas políticas de fiscalização e punição, por outro. Essa complementaridade é útil por três razões: a primeira refere-se às vantagens que existem em combinar várias ferramentas para solucionar o mesmo problema; a segunda refere-se às intervenções baseadas nas ciências comportamentais são direcionadas aos indivíduos que são desonestos de forma casual e que têm motivação intrínseca para a integridade, que, apenas, precisam de um "empurrãozinho" para agir de forma honesta. Para as pessoas sem essa motivação intrínseca e que são deliberadamente desonestas, a lei, fiscalização e punição devem ser as ferramentas prioritárias. Finalmente, a terceira razão refere-se ao facto de muitos casos de intervenções tradicionais anticorrupção, apesar de muito eficazes, foram desenhados sem consciência dos aspectos cognitivos, contextuais e sociais que podem influenciar o processo de tomada de decisão. Tomar consciência desses fatores, ajudaria a potencializar o resultado de políticas tradicionais através de pequenos ajustes, como o exemplo do código de conduta a ser assinado em um momento-chave, como sugerido acima. Portanto, a economia comportamental aplicada não é incompatível com as políticas tradicionais, mas oferece ferramentas para aprimorá-las e complementá-las. Dessa forma, incorporar as ciências comportamentais pode ser um fator fundamental aumentar o sucesso das estratégias de luta contra a corrupção no Brasil e ao redor do mundo.

\section{REFERÊnCIAS}

ANDERS, G. Civil servants in Malawi: cultural dualism, moonlighting and corruption in the shadow of good governance. 2005. Thesis (PhD) - University of Rotterdam, Rotterdam, 2005.

AQUINO, Karl; REED II, Americus. The self-importance of moral identity. Journal of Personality and Social Psychology, Washington, v. 83, n. 6, p. 1423-1440, dez. 2002.

ARIELY, Dan. A mais pura verdade sobre a desonestidade. Rio de Janeiro: Elsevier, 2012.

ASHFORTH, Blake; ANAND, Vikas. The normalization of corruption in organizations. Research in Organizational Behavior, Amsterdam, v. 25, p. 1-52, 2003.

AYAL, Shahar; GINO, Francesca. Honest rationales for dishonest behavior. In: MIKULINCER, Mario; SHAVER, Philip (Org.). The social psychology of morality: exploring the causes of good and evil. Washington: American Psychological Association, 2012. p. 149-166. 
BARKAN, Rachel et al. The pot calling the kettle black: distancing response to ethical dissonance. Journal of Experimental Psychology: General, Washington, v. 141, n. 4, p. 757-773, nov. 2012.

BARKAN, Rachel; AYAL, Shahar; ARIELY, Dan. Ethical dissonance: justifications, and moral behavior. Current Opinion in Psychology, New York, v. 6, p. 157-161, dec. 2015.

BAZERMAN, Max; LOEWENSTEIN, George; MOORE, Don. Why good accountants do bad audits. Harvard Business Review, Cambridge, v. 80, p. 96-103, nov. 2002.

BAZERMAN, Max; TENBRUNSEL, Ann. Blind spots: why we fail to do what's right and what to do about it. Princeton: Princeton University Press, 2011.

BOWLES, Samuel; GINTIS, Herbert. Schooling in capitalist America: educational reform and the contradictions of economic life. Chicago: Haymarket Books, 2011.

BURSZTYN, Leonardo et al. Moral incentives in credit card debt repayment: evidence from a field experiment. The National Bureau of Economic Research Working Paper, n. 21611, nov. 2017.

CAIN, Daylian; LOEWENSTEIN, George; MOORE, Don. The dirt on coming clean: perverse effects of disclosing conflicts of interest. Journal of Legal Studies, Chicago, v. 34, n. 1, p. 1-25, jan. 2005.

CAIN, Daylian; LOEWENSTEIN, George; MOORE, Don. When sunlight fails to disinfect: understanding the perverse effects of disclosing conflicts of interest. Journal of Consumer Research, Chicago, v. 37, n. 5, p. 836-857, feb. 2011.

CARLSMITH, J. Merrill; GROSS, Alan. Some effects of guilt on compliance. Journal of Personality and Social Psychology, Washington, v. 11, n. 3, p. 232-239, mar. 1969.

CLARKE, Ronald; FELSON, Marcus. Routine activity and rational choice: advances in criminological theory, v. 5, 1993.

FALK, Armin; SZECH, Nora. Organizations, diffused pivotality and immoral outcomes. 2013. Disponível em: <https://polit.econ.kit.edu/downloads/papers/Falk_Szech_WP_2_Pivotality_Fal_Szech_DP-2.pdf>. Acesso em: 2 maio 2018.

FOLTZ, Jeremy D.; OPOKU-AGYEMANG, Kweku A. Do higher salaries lowerpetty corruption? A policy experiment on West Africa's highways. 2015. Disponível em: <http://cega.berkeley.edu/assets/miscellaneous_ files/Opoku-Agyemang_WGAPE_2015.pdf>.

GINO, Francesca; AYAL, Shahar; ARIELY, Dan. Contagion and differentiation in unethical behavior: the effect of one bad apple on the barrel. Psychological Science, California, v. 20, n. 3, p. 393-398, mar. 2009.

GINO, Francesca; AYAL, Shahar; ARIELY, Dan. Self-serving altruism? The lure of unethical actions that benefit others. Journal of Economic Behavior \& Organization, Amsterdam, v. 93, p. 285-292, set. 2013.

GINO, Francesca; PIERCE, Lamar. Dishonesty in the name of equity. Psychological Science, Washington, v. 20, n. 3, p. 1153-1160, set. 2009.

GNEEZY, Uri; IMAS, Alex; MADARÁSZ, Kristóf. Conscience accounting: emotion dynamics and social behavior. Management Science, Maryland, v. 60, n. 11, p. 2645-2658, ago. 2014.

HAMMAN, John; LOEWENSTEIN, George; WEBER, Roberto. Self-interest through delegation: an additional rationale for the principal-agent relationship. American Economic Review, Tennessee, v. 100, n. 4, p. 1826-1846, set. 2010.

HARE, Robert. Psychopathy: a clinical and forensic overview. Psychiatric Clinics of North America, Amsterdam, v. 29, n. 3, p. 709-724, set. 2006.

HARFORD, Tim. The logic of life: the rational economics of an irrational world. New York: Random House, 
2008.

HENRICH, Joseph, et al. "Economic man" in cross-cultural perspective: behavioral experiments in 15 small-scale societies. Behavioral and Brain Sciences, New York, v. 28, n. 6, p. 795-855, dez. 2005.

HOUSER, Daniel; VETTTER, Stefan; WINTER, Joachim. Fairness and cheating. European Economic Review, Amsterdam, v. 56, n. 8, p. 1645-1655, nov. 2012.

HSEE, Christopher. Elastic justification: how tempting but task-irrelevant factors influence decisions. Organizational Behavior and Human Decision Processes, Amsterdam, v. 62, n. 3, p. 330-337, jun. 1995.

HSEE, Christopher. Elastic justification: how unjustifiable factors influence judgments. Organizational Behavior and Human Decision Processes, Amsterdam, v. 66, n. 1, p. 122-129, abr. 1996.

KALANTHROFF, Eyal; ASLAN, Chen; DAR, Reuven. Washing away your sins will set your mind free: physical cleansing modulates the effect of threatened morality on executive control. Cognition and Emotion, London, v. 31, n. 1, p. 185-192, 2017.

KUNDA, Ziva. The case for motivated reasoning. Psychological Bulletin, Washington, v. 108, n. 3, p. 480-498, nov. 1990.

LAMBSDORFF, Johann. Behavioural and experimental economics as a guidance to anticorruption. In: SERRA, Danila; WANTCHEKON, Leonard (Org.). New advances in experimental research on corruption. Bingley: Emerald Group Publishing Limited, 2012. p. 279-300.

LAMBSDORFF, Johann. Preventing corruption by promoting trust: insights from behavioral science. Passauer Diskussionspapiere: Volkswirtschaftliche Reihe, Passau, v. 69, n. 15, p. 1-16, 2015.

LOEWENSTEIN, G.; SUNITA, Sah; CAIN, Daylian. The unintended consequences of conflict of interest disclosure. The Journal of the American Medical Association, Chicago, v. 307, n. 7, p. 669-670, fev. 2012.

MARQUETTE, Heather; PEIFFER, Caryn. Corruption and collective action. Research Paper 32. Developmental leadership programme and U4 Anti-Corruption Resource Centre. Disponível em: $<$ http://publications.dlprog.org/CorruptionandCollectiveAction.pdf>.

MAZAR, Nina; AMIR, On; ARIELY, Dan. The dishonesty of honest people: a theory of self-concept maintenance. Journal of Marketing Research, Chicago, v. 45, n. 6, p. 633-644, dez. 2008.

MAZAR, Nina; ARIELY, Dan. Dishonesty in everyday life and its policy implications. Journal of Public Policy \& Marketing, Chicago, v. 25, n. 1, p. 117-126, mar. 2006.

MEAD, Nicole et al. Too tired to tell the truth: self-control resource depletion and dishonesty. Journal of Experimental Social Psychology, Amsterdam, v. 45, n. 3, p. 594-597, maio 2009.

MOORE, Celia; GINO, Francesca. Ethically adrift: how others pull our moral compass from true north, and how we can fix it. Research in Organizational Behavior, Amsterdam, v. 33, p. 53-77, 2013.

O’DONOGHUE, Ted; RABIN, Matthew. Doing it now or later. American Economic Review, Pittsburgh, v. 89, n. 1, p. 103-124, mar. 1999.

OECD. Recommendation of the Council for Development Co-operation Actors on Managing the Risk of Corruption: compendium of existing practices. DCD/DAC(2017)39. 2017. Disponível em: <http://www.oecd.org/ officialdocuments/publicdisplaydocumentpdf/?cote=DCD/DAC(2017)39\&docLanguage $=$ En $>$.

PERSSON, Anna; ROTHSTEIN, Bo; TEORELL, J. Why anticorruption reforms fail: systemic corruption as a collective action problem. Governance, New Jersey, v. 26, n. 3, p. 449-471, jul. 2013.

PLONER, Matteo; REGNER, Tobias. Self-image and moral balancing: An experimental analysis. Journal of Economic Behaviors and Organization, Amsterdam, v. 93, p. 374-383, set. 2013. 
PRUCKNER, Gerald; SAUSGRUBER, Rupert. Honesty on the streets: a field study on newspaper purchasing. Journal of the European Economic Association, New Jersey, v. 11, n. 3, p. 661-679, jun. 2013.

RANA Plaza owner jailed for three years over corruption. 29 August 2017. Disponível em: <https://www. aljazeera.com/news/2017/08/rana-plaza-owner-jailed-years-corruption-170829161742916.html>.

SACHDEVA, Sonya; ILIEV, Rumen; MEDIN, Douglas. Sinning saints and saintly sinners: the paradox of moral self-regulation. Psychological Science, Washington, v. 20, n. 4, p. 523-528, abr. 2009.

SAH, Sunita; LOEWENSTEIN G.; CAIN, Daylian. The burden of disclosure: increased compliance with distrusted advice. Journal of Personality and Social Psychology, Washington, v. 104, n. 2, p. 289-304, fev. 2013.

SCHIKORA, Jan. Bringing the four-eyes-principle to the lab. 2011. Disponível em: <https://epub.ub.uni-muenchen.de/12160/1/The4EP_Schikora.pdf>. Acesso em: 10 maio 2018.

SCHULZE, Günther; FRANK, Björn. Deterrence versus intrinsic motivation: experimental evidence on the determinants of corruptibility. Economics of Governance, Cham, v. 4, n. 2, p. 143-160, ago. 2003.

SHELDON, Oliver; FISHBACH, Ayelet. Anticipating and resisting the temptation to behave unethically. Personality and Social Psychology Bulletin, California, v. 41, n. 7, p. 962-975, jul. 2015.

SHU, L. et al. Signing at the beginning makes ethics salient and decreases dishonest self-reports in comparison to signing at the end. Proceedings of the National Academy of Sciences of the United States of America, Washington, v. 109, n. 38, p. 15197-15200, set. 2012.

SIEFF, Kevin. Low pay and one minor promotion for the most honest man in Afghanistan. The Washington Post, 31 jan. 2014. Disponível em: < https://www.theguardian.com/world/2014/jan/31/afghanistan-corruption-honest-police-officer>.

SIMON, H. A behavioral model of rational choice. The Quarterly Journal of Economics, Cambridge, v. 69, n. 1, p. 99-118, fev. 1955.

SOUSA, Luís de. Corrupção. Lisboa: Fundação Francisco Manuel dos Santos, 2011.

THALER, Richard; SUNSTEIN, Cass. Nudge: como melhorar as decisões sobre saúde, dinheiro e felicidade. Lisboa: Academia do Livro, 2009.

WILTERMUTH, Scott. Cheating more when the spoils are split. Organizational Behavior and Human Decision Processes, Amsterdam, v. 115, n. 2, p. 157-168, jul. 2011.

ZHONG, Chen-Bo; LILJENQUIST, Katie. Washing away your sins: threatened morality and physical cleansing. Science, Washington, v. 313, n. 5792, p. 1451-1452, set. 2006. 
Para publicar na revista Brasileira de Políticas Públicas, acesse o endereço eletrônico www.rbpp.uniceub.br

Observe as normas de publicação, para facilitar e agilizar o trabalho de edição. 